\title{
Land use change and environmental sustainability: the case of Lagos Metropolis
}

\author{
I. I. C. Nwokoro ${ }^{1} \&$ S. O. Dekolo ${ }^{2}$ \\ ${ }^{I}$ Department of Urban and Regional Planning, \\ University of Lagos, Nigeria \\ ${ }^{2}$ Department of Urban and Regional Planning, \\ Lagos State Polytechnic, Nigeria
}

\begin{abstract}
Land use is a most important factor in the distribution and functioning of ecosystems and benefits derived by man. The Malthusian geometric population growth and continuous demands for food, shelter, clothing, energy and even pleasure has led to depletion of natural resources. Land is limited in supply and its finite nature makes it a scarce resource that cannot meet its demand. The use of land is a reflection of our decisions, which will determine how sustainable our future will be. Detecting land use changes requires timely and accurate information which can be assured by using remotely sensed data and GIS. Analyzing the correlation between land use changes and their impacts is essential for spatial planning at various spatial levels (global, national, regional and local levels). A cursory look at the sporadic growth of the Lagos metropolis reveals an unquestionable exert of pressure on the existing rural land, agricultural and forests resources. This paper examines Spatio-temporal trends in land use and land cover changes in the Lagos Metropolitan region, especially the loss of forest resources and agricultural land to urban development. Landsat images were used to produce land use classification maps for a period spanning sixteen years (1990 and 2006). The study was limited to these two dates due to cost and difficulty of acquiring satellite imageries. The dynamics of land use change and its impact were discussed as major findings. The paper submits that effective spatial planning could minimize the impacts of land use changes that threaten biodiversity and ecosystems though timely and proper monitoring using remote
\end{abstract}


sensing and GIS; it also recommends integrated spatial planning approach and deployment of environmental management plans.

Keywords: land use change, sustainable development, remote sensing, geographic information systems, urban growth.

\section{Introduction}

Environment has been defined broadly as all the elements that surround an organism; this includes the physical, chemical and biotic conditions [1]. Man's environment includes the biosphere, atmosphere, lithosphere, and the hydrosphere. He interacts with these four spheres for his day to day survival but dominates and often destroys these components of the environment, which he depends on and ultimately becomes vulnerable.

Avoiding vulnerability requires a better understanding of the ecological patterns and processes and integration of sustainability strategies in the land use management processes to protect and preserve the biodiversities while meeting the ever increasing demand of population growth and spatial expansions of cities [2].

Cities expansion in developing countries and the global south is characterized by sprawling fractals or spider-like configurations rather than compact aggregations seen in the developed world. The consequence of the sporadic growth and sprawling development especially in rapidly growing metropolitan regions is reflected in problems like climate change, resource depletion and diminution of agro-ecological and rural lands [3].

Land use and land cover changes due to city expansion have serious ecological repercussions and pose a great deal of challenge to environmental sustainability at local and global scales. The last few decades have witnessed a threat potentially undermining the capacity of ecosystems to sustain food production, maintain freshwater and forest resources, regulate climate and air quality. We are faced with the challenge of ensuring "sustainable development", which tends to manage the trade-offs between immediate human needs and maintaining the capacity of the biosphere to provide goods and services in the long term $[4,5]$.

Sustainable development has become a leading principle for land use planning theory and practice; it is multidimensional, involving the maintenance of natural resources and spatial patterns of land use that are ecologically, socially and economically beneficial [6]. In literature, there are genuine concerns about the ecological dimensions of land use planning as well as the human ecosystems framework, which integrates spatial and social dimensions of urban ecosystems $[3,7]$.

However, a candid look at the sprawling expansion of Lagos metropolis reflects ineffective and unsustainable land use planning decisions and actions (or inaction), which has led to physical, socio-economic and environmental problems. To reverse this trend there is need for holistic knowledge of the region's land use activities and long term environmental impacts. Land use and 
land cover change patterns must be understood at various spatial and temporal scales to predict future behaviour, change and achieve sustainable city growth.

In this paper, remotely sensed images were used to examine land use and land cover changes over a 15 -year period with the aim of understanding the spatiotemporal trends and their consequences. The paper will be concluded by recommendations to promote sustainability.

\section{The study area: Lagos metropolis}

Lagos metropolis is a continuous built up area, which covers about $33 \%$ of the entire area of Lagos State. Spatially Lagos State is the smallest state in Nigeria but having its most populous city and the $2^{\text {nd }}$ fastest growing megacity in Africa after Cairo. The city originated from a small fishing settlement in Lagos Island, which later became the seat of the British Colonial government in 1861. As at 1871 the city had a population of 28,520 people with an area of $4.02 \mathrm{sq} . \mathrm{km}$ (see table 1).

By 1963 when Nigeria became a Republic, it population had grown to 665,250 with an area of 69.96 sq. $\mathrm{km}$. Lagos still maintained its position as the administrative capital of Nigeria until 1991 when the seat of the federal government was moved to Abuja; the population of the metropolis had risen to about 5.3 million which was $95 \%$ of the total population of the state covering an area approximately $1,183 \mathrm{sq}$. $\mathrm{km}$ out of the $3,577 \mathrm{sq}$. km. area of Lagos State. It is worthy of note that only 728 sq. $\mathrm{km}$ (i.e. $61.54 \%$ ) of the metropolis is land area, while the rest $455 \mathrm{~km} 2$ (i.e. $38.46 \%$ ) is wet land, marshy and water logged.

Table 1: $\quad$ Population of Lagos Colony and Lagos State (Source: Population of Nigeria, 1963, Lagos Vol. 1 and 2, FOS; National Population Census, 1991; National Population Census 2006).

\begin{tabular}{|l|r|r|r|r|}
\hline $\begin{array}{l}\text { Census } \\
\text { Year }\end{array}$ & $\begin{array}{r}\text { Area } \\
\mathrm{Km}^{2}\end{array}$ & Urban & $\begin{array}{r}\text { Rural } \\
\text { /Suburban }\end{array}$ & Total \\
\hline 1871 & 4.02 & 28,520 & n.a & 28,520 \\
\hline 1881 & 4.02 & 37,450 & n.a & 37,450 \\
\hline 1891 & 4.02 & 32,510 & n.a & 32,510 \\
\hline 1901 & n.a & 41,850 & n.a & 41,850 \\
\hline 1911 & 46.63 & 73,770 & n.a & 73,770 \\
\hline 1921 & 52.25 & 99,690 & n.a & 99,690 \\
\hline 1931 & 66.29 & 126,110 & n.a & 126,110 \\
\hline 1950 & 70.52 & 230,260 & n.a & 230,260 \\
\hline 1952 & 69.95 & 271,800 & 238,432 & 510,232 \\
\hline 1963 & 69.95 & 665,246 & 778,321 & $1,443,567$ \\
\hline 1991 & 3577 & $5,260,771$ & 425,010 & $5,685,781$ \\
\hline 2006 & 3577 & $7,937,932$ & $1,175,673$ & $9,113,605$ \\
\hline
\end{tabular}

Many have attributed the reason for the speedy growth of Lagos being migration from other parts of the country to look for better opportunities, more 
so, being the capital city. However, the city had continued to experience rapid urban growth even after being stripped of this status. By 2006, the city had extended beyond the administrative boundary of the state and attained a megacity status (i.e. having a population exceeding 10 million people). This is referred to as the Greater Metropolitan Lagos or Lagos Megacity Region, which is a continuous built up area spanning over 153,540 hectares of land comprising virtually all the Local Government Areas of Lagos State and four LGAs (i.e., Sagamu, Owode, Ifo and Ado-Odo/Otta) in the neighbouring Ogun State [8].

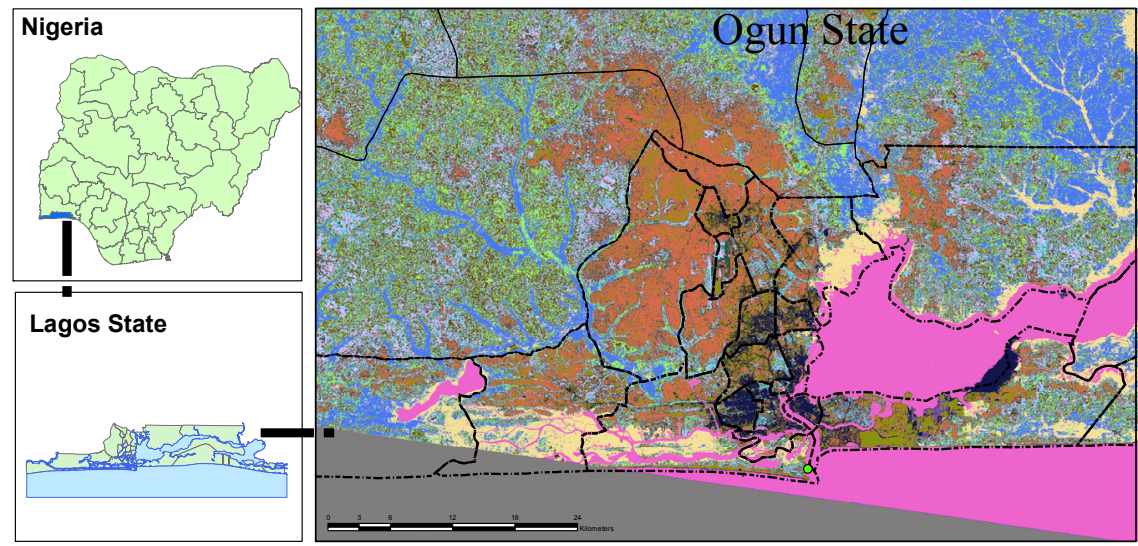

Figure 1: Lagos Metropolis refers to a geographical perception of continuous urban development as shown above in red patches, which has extended beyond the Lagos State's boundary. However, for this research, it has been delimited to areas of continuous growth within the Lagos State administrative area. (See online for a colour version of this figure.)

Recent studies by the United Nations on World Urbanization Prospects have ranked Lagos $9^{\text {th }}$ among the 28 current and prospective megacities in the world with a standard of living score of $19 \%$. It is expected to accommodate about 24.4 million people that in 2015 (barely four years away) acquiring the status of the $3^{\text {rd }}$ largest megacity in the world trailing behind Japan's 28.7 million and Bombay's 27.4 million [9].

\section{Conceptual frameworks}

Land has often been described as the foundation of all forms of human activities. It is from it we obtain food, shelter and space for every other activity. Being described as a resource it has economic value; however it is finite because the supply available for human use is limited in the physical sense. Apart from atmospheric resources, man's natural resources (renewable or non-renewable) are land based; therefore, the use of land must also be within environmental or sustainability limits [10]. Land use takes place within the following frameworks: 
environmental (physical and ecological), economic, social and institutional frameworks.

\subsection{Concepts of land use and land cover}

Land-use and Land-cover are two different concepts that has become a central component in current strategies for managing natural resources and monitoring environmental changes. Land-use emphasizes more on land's social properties; it is the output of activities that human adopts to manage and regulate the land chronically and periodically according to determinate economic and social purposes. Thus, land-use is a process of turning natural ecosystem into social ecosystem, and the process is a complicated procedure by the synthetic effect from nature, economy and society. The manner, degree, structure, area distributing and benefit of land-use are not only affected by natural condition but also restricted by diversified natural, economic and technologic condition, and in sometimes among all factors the social production form is determinant land use is the most direct and leading driving factor to the land cover change $[11,12]$.

To simplify the link between land use and land cover, the concept of land use is said to be characterized by the arrangements, activities and inputs people undertake in a certain land cover type to produce, change or maintain it. Landcover on the other hand emphasizes particularly on its natural properties and it is defined as the biophysical cover of the earth's surface and it is the expression of human activities and synthetically reflection of various elements in global surface covered with natural body or man-made features. Hence land cover is the geographic feature which may form a reference base for applications ranging from forest monitoring, planning biodiversity, climate change, etc. [12].

Since land cover represents the resource base of our ecosystem, which is going through continuous change in time and space, the lack of appropriate data in developing countries had made it difficult to assess the present and future impacts of the changes on the ecosystem (human and nature). However, Improved land cover and land use information as suggested by this research is vital for planning and predicting future scenarios, which will ensure sustainable land use in our city-regions.

\subsection{Concepts of sustainable development and land use change}

Land use change is central to the sustainability debate; it is a major driving force of global environmental change and it affects the earth systems as seen in literature $[5,8,13]$. Since the Stockholm Conference in 1972 the need for managing environmental resources has become a political agenda in most developed countries of the world. The awareness was raised to its peak at the Rio Earth Summit in 1992 by the global action programme on sustainability Agenda 21.

The concept of sustainable development has since move from the environmental conservationist paradigm to a holistic model which seeks to deliver basic environmental, social and economic services to all residents of a community without threatening the viability of the natural, built and social 
systems upon which the delivery of these services depends [10]. De Wit and Verhey [14] identified four interlinked dimensions of sustainable development. These are the environmental, economic, social and institutional dimensions.

Environmental dimension: This generally deals with maintaining stock of natural resources above certain thresholds. It includes biodiversity preservation, monitoring resource depletion, ensuring non-renewable resources are preserved for the future generation and mitigating environmental impact.

Economic dimension: This ensures a steady and continuous stream of income for everyone and at different levels, thereby eradicating poverty among households, communities and countries. There is a thrust to increase food production and real income, promote efficient investment, maintain productivity at all times and derive economic benefit from land.

Social dimension: It is aimed at ensuring equitable access to resources, information and services. It also protects acquired rights to land and promotes active stakeholders participation in law and policy development. Sustainability also ensures redistribution of wealth derived from land resources, while ensuring accountability and proper management land resources benefits.

Institutional dimension: It will be practically impossible for the three dimensions mentioned above to be achieved without the establishment of formal and informal institutions that will exercise its political will for sustainability.

Moreover, due to the overwhelming importance of land use decisions in achieving sustainable development, Chapter 10 of Agenda 21 affirmed that land use planning was essential in achieving an integrated approach to planning and management of land resources [14].

\subsection{Conceptual framework for land use change detections}

Land use change detection is a process used in remote sensing to determine changes in land cover properties between different periods to monitor and manage natural resources and urban development by providing quantitative analysis of spatial patterns [15]. Change detection techniques could be grouped into two: pre-classification and post classification methods. Pre-classification methods applied in similar studies include image differencing, image regression and vegetation index differencing [16].

Post classification methods comprise of comparing independently classified images for different temporal periods to produce a change map and change statistics. They are mostly suitable and applied in land use change studies because of the straightforwardness and simplicity in post classification comparison [15]. In this research, post classification method will be utilized for the periods under study.

\section{Methodology}

In order to facilitate land use change detection in this research, the satellite images was classified and interpreted using an unsupervised method. Most GIS and remote sensing software have in-built classification schemes and algorithms; 
Isodata cluster building was adopted and the study area was classified into seven classes and maps were generated. The final output classes were: major urban, minor urban, forested freshwater swamps; riparian forests; cultivated farmlands, water bodies and no data (see table 3 ).

Furthermore, municipalities or local government which were not fully covered by the satellite imageries used and areas outside the administrative boundaries of Lagos State were clipped off in ArcGIS, thereby delimiting the study area to $1274 \mathrm{~km}^{2}$ (i.e. $36 \%$ of the total area of Lagos State) and 15 out of 20 Local Government Areas in the state.

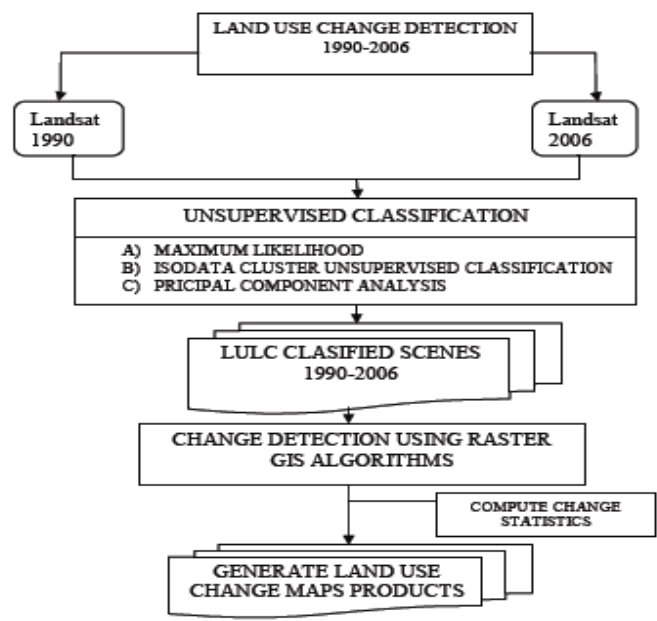

Figure 2: Research workflow.

\subsection{Data sources}

Remote sense data for the temporal period under investigation (i.e. 1990 and 2006) were acquired from USGS/EROS website for free. 30 meters Landsat low resolution imageries were used to detect changes. Images were pre-processed for geometrical correction and noise removal before classification. Satellite

Table 2: $\quad$ Datasets used in the research.

\begin{tabular}{lllllll}
\hline $\begin{array}{l}\text { Acquisition } \\
\text { Date }\end{array}$ & $\begin{array}{l}\text { Satellite } \\
\text { Number }\end{array}$ & $\begin{array}{l}\text { Sensor } \\
\text { Type }\end{array}$ & $\begin{array}{l}\text { WRS } \\
\text { Path/Row }\end{array}$ & $\begin{array}{l}\text { UTM } \\
\text { Zone }\end{array}$ & Datum & $\begin{array}{l}\text { Spatial } \\
\text { Resolution } \\
\text { (Metres) }\end{array}$ \\
\hline $\mathbf{0 7 / 1 2 / 2 0 0 6}$ & Landsat 7 & ETM+ & $191 / 55$ & $31 \mathrm{~N}$ & WGS84 & 30 \\
$\mathbf{2 7 / 1 2 / 1 9 9 0}$ & Landsat 4 & TM & $191 / 55$ & $31 \mathrm{~N}$ & WGS84 & 30 \\
Supporting Demographic Data & & & & \\
$\mathbf{2 0 0 6 , 1 9 9 1}$ & $\begin{array}{l}\text { National Population } \\
\text { Census }\end{array}$ & $\begin{array}{l}\text { Population of Lagos } \\
\text { State/Colony }\end{array}$ \\
\hline
\end{tabular}


imageries were imported into ArcGIS and Ilwis GIS Software environment where maps and change statistics were computed.

\section{Discussion on findings}

Land use is a major driver of environmental and climatic change [13]; these changes are induced in the atmosphere, hydrosphere, lithosphere and biosphere directly or indirectly through man's activities; thereby, leading to unsustainable environmental conditions like water and air pollution, loss of biodiversity, land degradation, food insecurity, etc.

A closer look at the output of the imageries classified in figure 3 reveals the extents of continuous urban growth of the city. Table 3 shows that there was an overall 30\% loss of agro-ecological zone, with the built up areas (major and minor urban land uses) rising from $31 \%$ to $48 \%$ within the study period. This will bring challenge of sustainability as discussed in detailed below.
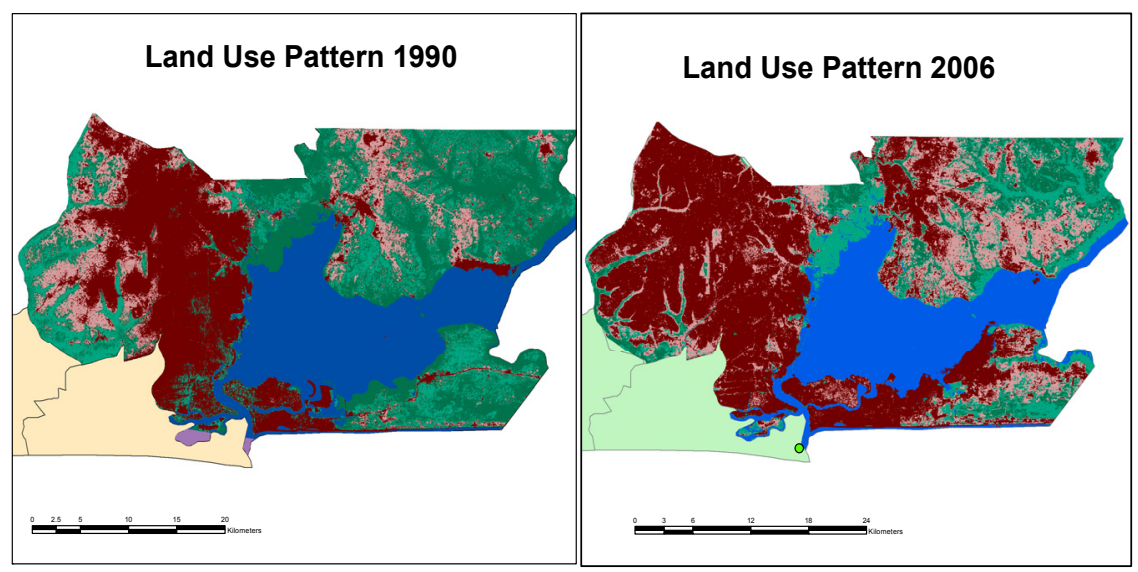

Figure 3: $\quad$ Classified Imageries for land use patterns between 1990 and 2006.

Table 3: $\quad$ Land use patterns for 1990 and 2006.

\begin{tabular}{|l|r|r|r|r|r|l|}
\hline LULC Classification & \multicolumn{1}{|c|}{$\begin{array}{r}\text { Area } \\
\text { (ha) }\end{array}$} & $\begin{array}{r}\mathbf{2 0 0 6} \\
\mathbf{\%}\end{array}$ & $\begin{array}{r}\text { Area } \\
\text { (ha) }\end{array}$ & $\begin{array}{r}\text { \% } \\
\text { \% }\end{array}$ & Change & Remarks \\
\hline Waterbody & 27423 & 21.54 & 25754 & 20.23 & -1.31 & Decrease \\
\hline Riparian Forest & 43272 & 33.99 & 19798 & 15.55 & -18.44 & Decrease \\
\hline $\begin{array}{l}\text { Forested Freshwater } \\
\text { Swamp }\end{array}$ & 9237 & 7.26 & 6612 & 5.19 & -2.07 & Decrease \\
\hline Cultivated Farmlands & 7206 & 5.66 & 14111 & 11.09 & +5.43 & Increase \\
\hline Minor Urban & 7071 & 5.56 & 8106 & 6.37 & +0.81 & Increase \\
\hline Major urban & 32611 & 25.62 & 52908 & 41.57 & +15.95 & Increase \\
\hline No Data & 469 & 0.37 & 0 & 0 & N.A. & Not Applicable \\
\hline & $\mathbf{1 2 7 2 8 9}$ & $\mathbf{1 0 0}$ & $\mathbf{1 2 7 2 8 9}$ & $\mathbf{1 0 0}$ & & \\
\hline
\end{tabular}




\subsection{Assessment of land use change between 1994 and 2006}

Looking at table 3 above, there was a loss of $1.31 \%$ of the water bodies during the study period. This may be due to reclamation and sand filling of water fronts, swamps and the Lagos lagoon for residential development. This is a practice by the Lagos State government and individuals that has been widely condemned $[17,18]$. Some high profile estates in Lagos were sand filled and the government is presently proposing reclaiming part of the Atlantic Ocean for its mega project, "Eko Atlantic City".

Other notable changes include the loss of forest reserves and freshwater swamps, which reduced by approximately $20 \%$ land to built-up urban development. The satellite imagery in figure 3 shows that there is an increase of is also a seemingly movement of people to the suburbs like Ikorodu and Alimosho where land is cheaper and accessible. This trend can be seen in the housing units sprawling all over the suburb landscape.

The result also reveals a 5\% rise in cultivated farmland. This may not be far from new policies of the Lagos State government to encourage and participate in farming. For example, the fish farm estate and other projects in Ikorodu.

\section{Conclusion}

This study has shown that between 1990 and the year 2006, there was significant decrease in the forest resources in the study area. Between these periods, over $20 \%$ of forest and fresh water swamps was lost to build up areas. It is obvious that if these patterns of land use change continue it is likely that in the nearest future much will be left undesired.

Moreover, using remote sensing and GIS to analyse land use changes have also provided insight to the current trend in resource depletion, deforestation and loss of biodiversity in the ever growing city, thereby bringing to fore its future negative implications, which requires the attention of planners and policy makers in order to achieve sustainability now and in the future. In a nutshell, there is a need to urgently address the depletion of the forest and water resources in Lagos Metropolis. The research established remote sensing and GIS as a viable tool for natural resource management in the developing countries.

\subsection{Policy implication and recommendations}

The management of land based resources in our cities is statutorily the responsibility of government; however, failure in this responsibility can be attributed to lack of baseline information on available resources (water, forest, land, etc). It is imperative that managing such vulnerable resources requires reliable and updated information about what exists and trend of use in the past and present). Since remote sensing and GIS remains one of the most reliable technologies for collecting, storing, retrieving and analyzing land based resource' information, it is suggested that GIS technology be adopted by land managers in the city's municipalities or local government councils as well as 
other government and non-governmental agencies dealing with land use management. This is because a well informed land use decision will enhance sustainable development.

\section{References}

[1] Allaby, M., Dictionary of the Environment, Macmillan Press: London, 1977.

[2] Niemelä, J. "Ecology and urban planning." Biodiversity and Conservation, 8(1), pp. 119-131, 1999.

[3] Pickett, S T A, et al. "Ecological, Physical, and Socioeconomic Components of Metropolitan Areas." Annual Review of Ecolological Systems, 32, pp. 127-157, 2001.

[4] Foley, J. A., Global Consequences of Land Use, Science, 309(5734), pp. 570-574, 2005.

[5] Welbank, Micheal. "In the Beiginning was the Phrase." Planning Week, pp. 14-17, 1994

[6] Leitao, Andre Botequilha, and Jack Ahern. "Applying Landscape Ecological Concepts and Metrics in Sustainable Landscape Planning." Landscape and Urban Planning, 59 (2), pp. 65-93, 2002.

[7] Grimm, N. B., et al. "Global Change and the Ecology of Cities." Science, 319(5864), pp. 756-771, 2008.

[8] Federal Government of Nigeria. Report of the Presidential Committee on Redevelopment of Lagos Megacity Region. Lagos: Federal Government of Nigeria, 2006.

[9] UNFPA. State of the World Population 2007: Unleashing the Potential of Urban Growth. New York: United Nations Population Fund, 2007.

[10] Beale, J. G., The Manager and the Environment, Pergamon Press: Oxford, pp. 211. 1980.

[11] Brandon, R. B., Mapping Rural Land Use \& Land Cover Change In Carroll County, Arkansas Utilizing Multi-Temporal Landsat Thematic Mapper Satellite Imagery. University of Arkansas, Fayetteville: Centre of Advanced Spatial Technologies, 2000.

[12] Dekolo, S. O. \& Ogunleye, F., Application of Remote Sensing and GIS to Monitor Land Use Changes in Ibeju Lekki, Lagos. OOU Journal of Environmental Technology, 1(1) pp. 34-41, 2007.

[13] Shao, Jingan, Jiupai Ni, Chaofu Wei, and Deti Xie. "Land Use Change and its Corresponding Ecological Response: A Review." Journal of Geographical Sciences 15 (3), pp. 305-328, 2005.

[14] DeWit, P. \& Verheye, W., Land Use Planning for Sustainable Development. In Land Cover and Land Use, UNESCO-EOLSS Publishers: Oxford, 2003.

[15] Araya, Y. H., Urban Land Use Change and Modeling: A Case Study of Setubal and Sesimbra, Portugal, Master Thesis, Institute for Geoinformatics, university of Munster, Munster: University of Munster, 2009. 
[16] Aronoff, S., Remote Sensing for GIS Managers. ESRI Press: Redlands, pp. 287-335, 2005.

[17] Nwafor, J C. "Physical Environment, Decision-making and Land Use Development in Metropolitan Lagos." Geojournal, 12(4), pp. 433-442, 1986.

[18] Okparaocha, C., "Environmental Expert Reveals Problems Land Reclamation Creates." Nigerian Tribune, p.7, 13 February 2012. 